\title{
PREVALENCE OF FATTY LIVER AND ITS ASSOCIATION WITH HIGH TOTAL CHOLESTEROL IN PEOPLE OF TUMKUR, INDIA
}

\author{
Kolar Venkataravanappa Vineetha1, Sorikunte Huchappa Anand², Kambathnahalli Paramashivaiah Suresh Babu³ \\ ${ }^{1}$ Assistant Professor, Department of Medicine, Sree Siddhartha Medical College. \\ ${ }^{2}$ Associate Professor, Department of Radiodiagnosis, Sree Siddhartha Medical College. \\ 3Professor, Department of Medicine, Sree Siddhartha Medical College.
}

\begin{tabular}{l}
\hline ABSTRACT \\
BACKGROUND \\
To study the prevalence of fatty liver and its association with high total cholesterol through routine health check-up in people of \\
Tumkur.
\end{tabular}

\section{MATERIALS AND METHODS}

Data was collected from healthy individuals who underwent routine health check-up in Sree Siddhartha Medical College, Tumkur from July 2015 to December 2015. A total of 883 people underwent health check-up, who were also measured with certain biochemical parameters including total cholesterol. Abdominal ultrasonography was done for these subjects and they were grouped into fatty liver (diseased) and without fatty liver (normal).

\begin{abstract}
RESULTS
Among the analysed 875 subjects, 527 subjects had fatty liver (diseased) and 348 were without fatty liver (normal). The overall prevalence of fatty liver among people of Tumkur was found to be around $60 \%$. The mean total cholesterol of diseased subjects when compared with mean total cholesterol of the normal subjects was found to be significant $(p=0.0014)$.
\end{abstract}

\section{CONCLUSION}

Subjects with high total cholesterol can be screened for fatty liver and vice versa, as there is an association between fatty liver and total cholesterol.

\section{KEYWORDS}

Fatty Liver, Cholesterol, Tumkur.

HOW TO CITE THIS ARTICLE: Vineetha KV, Anand SH, Babu KPS. Prevalence of fatty liver and its association with high total cholesterol in people of Tumkur, India. J. Evolution Med. Dent. Sci. 2017;6(16):1264-1267, DOI: 10.14260/Jemds/2017/275

\section{BACKGROUND}

Non-Alcoholic Fatty Liver Disease (NAFLD) is defined as histopathological fat accumulation of $>5 \%$ of the liver weight. However, it can be defined as the presence of fatty liver at Ultrasonography (USG) in a clinical practice setting.[1,2] NAFLD is a manifestation of metabolic syndromes like obesity, type 2 diabetes mellitus, hypertension and dyslipidaemias. It can coexist with dyslipidaemia, which can ultimately lead to atherosclerosis. Progression to nonalcoholic steatohepatitis, cirrhosis and hepatocellular carcinoma is very much possible in cases with NAFLD. The prevalence of NAFLD is steadily increasing over the past 20 years in Western countries. It is now increasingly seen in south Asian countries, who have comparatively lean BMI.[3,4] NAFLD, as the name suggests is seen in non-alcoholics characterised by excessive fat accumulation and degeneration of hepatocytes and histologically presents as macrovesicular steatosis.[3,5]

Financial or Other, Competing Interest: None.

Submission 11-01-2017, Peer Review 10-02-2017,

Acceptance 16-02-2017, Published 23-02-2017.

Corresponding Author:

Dr. Kolar Venkataravanappa Vineetha,

Adarsha Krupa,

$6^{\text {th }}$ Cross,

Channabasaweshwara Nagar,

Upperhalli, Tumkur.

E-mail:drvineetha.anand@gmail.com

DOI: 10.14260/jemds/2017/275
USG is a non-invasive, safe, easily accessible, radiation free investigative modality and widely used in the diagnosis of NAFLD, although the gold standard for diagnosing NAFLD is liver biopsy.[3,5,6] The most common ultrasound criteria reported for diffuse hepatic fatty infiltration are parenchymal brightness, deep-beam attenuation, vascular blurring (loss of echoes from the walls of the portal veins) and increasing discrepancy of echogenicity between the liver and kidney parenchyma (hepatorenal index). Among these criteria, deepbeam attenuation has presented better performance for diagnosing fatty liver disease.[6,7]

A high Total Cholesterol (TC) level is associated with the risk of coronary heart disease ${ }^{[8,9]}$ and abnormal glucose metabolism.[6] We investigated the prevalence of NAFLD in association with total cholesterol levels whether it is significantly associated with those with high total cholesterol levels.

\section{MATERIALS AND METHODS}

Participants were selected who came to Sree Siddhartha Medical College, Tumkur for routine health examination. Data collected from the health camp from July 2015 to December 2015 were tabulated and results were analysed. Healthy volunteers whoever walked into the health camp were enrolled into this study. Subjects with chronic alcoholism, previous jaundice and liver diseases were excluded based on the history and clinical examination. 
Routine ultrasonography abdomen was done in curvilinear probe of $2-5 \mathrm{MHz}$ of GE Voluson 730 pro machine. Biochemical blood tests were conducted by ERBA EM 200 including fasting plasma glucose, levels of triglyceride and total, low and high-density lipoprotein (LDL, HDL) cholesterol. The definition of hypertension was systolic blood pressure $\geq 140 \mathrm{mmHg}$ or diastolic blood pressure $\geq 90$ mmHg. The cut points of hyperglycaemia, hypercholesterolaemia and hypertriglyceridaemia were fasting sugar $\geq 126 \mathrm{mg} / \mathrm{dL}, \mathrm{HDL}<40 \mathrm{mg} / \mathrm{dL}$, total cholesterol $\geq 200 \mathrm{mg} / \mathrm{dL}$ and triglyceride $\geq 150 \mathrm{mg} / \mathrm{dL}$. Abdominal ultrasonography examinations were performed using realtime convex-type of transducer with $3-5 \mathrm{MHz}$. Two internal medicine specialists who were blind to the medical history and blood test results of the examinees. The definition of ultrasonic fatty liver was based on a comparative assessment of image brightness relative to the kidneys, in line with previously reported diagnostic criteria. Severity of fatty liver was classified according to the following modified scoring system: brightness compared to kidneys $(0-3)$, blurring of gall bladder wall $(0-3)$, blurring of hepatic veins $(0-3)$, blurring of portal vein $(0-3)$, far gain attenuation $(0-3)$. Severity was defined as mild (total scores of 2-6), moderate,(7-10) and severe(11-15) fatty liver.

\section{Statistical Analysis}

Statistical analysis was performed using SAS version 9.4 and graphs using JMP version 12. Distribution of data was represented using histogram (Figure 3). Numerical variables are expressed as mean \pm standard deviation and categorical variables as percent (\%). Normality of the data was verified using Kolmogorov-Smirnov test; it was observed that data is skewed (non-normal). Non-parametric test, Mann-Whitney (Wilcoxon rank sum) test was applied to compare difference between Fatty liver and Normal group. Bar chart with mean +/- SE was represented. All analysis was carried out at $5 \%$ level of significance.

\section{RESULTS}

A total of 883 subjects were enrolled in this study that were eligible according to inclusion and exclusion criteria explained above. All the subjects enrolled were healthy subjects and did not have any acute disease. Out of which, data of 875 subjects were analysed. Eight subjects whose total cholesterol values were not available, have not been analysed. Among the 875 subjects 527 subjects had fatty liver (Disease) and 348 were without fatty liver (Normal) subjects. Majority of them were males constituting $93.5 \%$ of total subjects. Disease status by sex is represented by Figure 1 . And the age group of the recruited subjects ranged from 20 60 years. The mean age of the subjects in the diseased group was 43.1 years, while the mean age in the normal group was 36.3 years.

The prevalence of fatty liver in people of Tumkur was found to be around $60 \%$. When considered age group wise, $24.7 \%$ of total subjects in the fatty liver group belonged to 40 - 49 age group and $12.8 \%$ of total subjects in the normal group belonged to 20 - 29 age group. However, the 30 - 39 age groups presented almost equal distribution in the diseased (14.7\%) and normal (11.4\%) subjects. Table 1 represents the number of diseased and normal subjects and its mean total cholesterol values with regard to age group. Figure 2 represents the disease status by age group. And with respect to mean total cholesterol of the individual age groups for the diseased and the normal category did not differ much from the mean total cholesterol values for the total subjects. Gender wise, $62 \%$ of males had fatty liver while only about $14 \%$ of females had fatty liver. The prevalence was 4.5 fold higher among males than females.

The mean total cholesterol obtained for diseased subjects was $195.38 \mathrm{mg} / \mathrm{dL}(\mathrm{SD}=47.58)$ and the mean total cholesterol obtained in normal subjects was $185.10 \mathrm{mg} / \mathrm{dL}$ ( $\mathrm{SD}=44.50)$. The minimum and maximum values of total cholesterol were also higher in the diseased $(\mathrm{min}=100$ $\mathrm{mg} / \mathrm{dL}, \max =433 \mathrm{mg} / \mathrm{dL})$ than the normal $(\mathrm{min}=81 \mathrm{mg} / \mathrm{dL}$ $\max =387 \mathrm{mg} / \mathrm{dL}$ ) subjects. The $75 \%$ quartile and median values obtained for diseased subjects were $220 \mathrm{mg} / \mathrm{dL}$ and $190 \mathrm{mg} / \mathrm{dL}$ respectively and for normal subjects these were $209.5 \mathrm{mg} / \mathrm{dL}$ and $180 \mathrm{mg} / \mathrm{dL}$ respectively. Table 2 represents the quartiles Q1, Q2 and Q3 for the diseased and normal subjects. The mean total cholesterol for diseased subjects when compared with the mean total cholesterol of normal subjects was found to be significant ( $p=0.0014)$. Pearson correlation was applied to evaluate relationship between Age (years) and Total cholesterol (mg/dL). No statistically significant correlation was observed. Mixed model using sex, age (years) as covariate was carried out and it was found that sex and age (years) has no effect on Total Cholesterol $(\mathrm{mg} / \mathrm{dL})$.

Normality of the data was verified using KolmogorovSmirnov test; it was observed that data is skewed (nonnormal). Non-parametric test, Mann-Whitney (Wilcoxon rank sum) test was applied to compare difference between fatty liver and normal group. The p-value obtained was 0.0014 , which is less than 0.05 which means that the high cholesterol values which are seen in fatty liver subjects when compared to normal subjects was significant. And when Kruskal-Wallis test was applied the p-value obtained was 0.0017 , which is also $<0.05$ and showed significant difference between the diseased and normal subjects groups.

\begin{tabular}{|c|c|c|c|c|}
\hline $\begin{array}{c}\text { Age } \\
\text { Group }\end{array}$ & $\begin{array}{c}\text { Diseased } \\
\text { (n=527) }\end{array}$ & $\begin{array}{c}\text { Normal } \\
\text { (n=348) }\end{array}$ & $\begin{array}{c}\text { Mean TC } \\
\text { (mg/dL) } \\
\text { Diseased }\end{array}$ & $\begin{array}{c}\text { Mean TC } \\
\text { (mg/dL) } \\
\text { Normal }\end{array}$ \\
\hline $20-29$ & $37(4.2 \%)$ & $112(12.8 \%)$ & 187 & 176.81 \\
\hline $30-39$ & $130(14.9 \%)$ & $100(11.4 \%)$ & 196.43 & 185.76 \\
\hline $40-49$ & $216(24.7 \%)$ & $89(10.2 \%)$ & 198.14 & 189.91 \\
\hline $50-59$ & $140(16 \%)$ & $46(5.3 \%)$ & 192.64 & 194.95 \\
\hline $\begin{array}{c}60 \text { and } \\
\text { above }\end{array}$ & $4(0.5 \%)$ & $1(0.1 \%)$ & 185.75 & 169 \\
\hline \multicolumn{4}{|c|}{ Table 1. Age Group Wise Mean Total } \\
\hline
\end{tabular}

\begin{tabular}{|c|c|c|}
\hline Quartiles & Diseased & Normal \\
\hline $\mathrm{Q}_{1}$ & 161 & 154 \\
\hline $\mathrm{Q}_{2}$ & 190 & 180 \\
\hline $\mathrm{Q}_{3}$ & & \\
\hline \multicolumn{2}{|c|}{ Table 2. Quartiles in Diseased and Normal Subjects } \\
\hline \multicolumn{2}{|c}{} \\
\hline \multicolumn{2}{|c|}{} \\
\hline
\end{tabular}




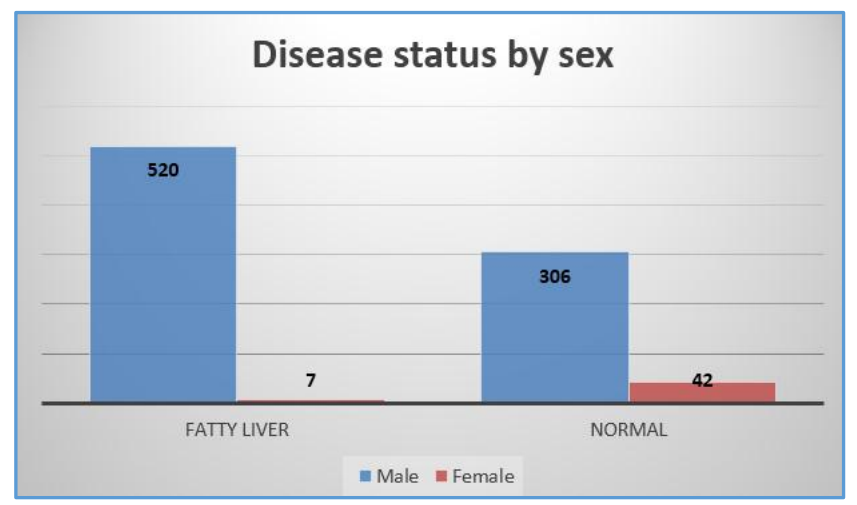

Figure 1. Disease Status by Sex

\section{Disease status by age group}

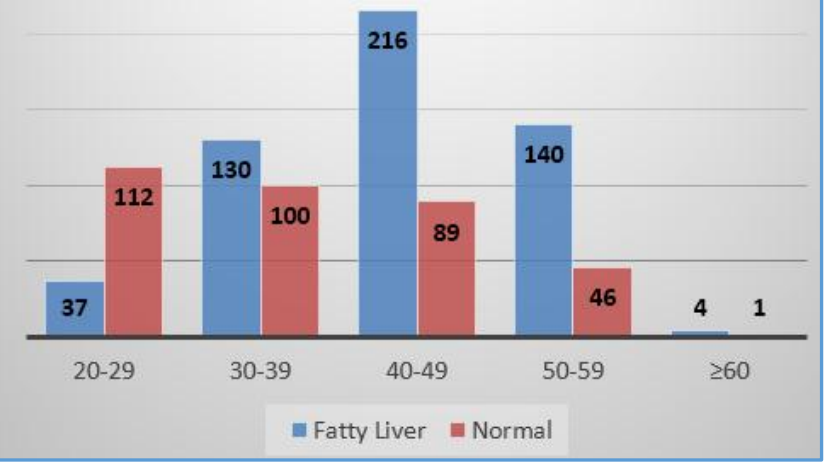

Figure 2. Disease Status by Age Group

\section{DISCUSSION}

NAFLD can range from simple fatty liver, steatohepatitis and fatty liver cirrhosis to hepatocellular carcinoma. The noninvasive ultrasonography is very useful in identifying the fatty liver in health camps, while screening the general population. Prevalence of fatty liver ranged from $17 \%$ to $46 \%$ in Asian countries according to Liao X-H et al.[10] However, in this study we found the prevalence to be around $60 \%$ of the general population, which is much higher compared to other Asian populations. The higher prevalence in this study could be due to unequal distribution of gender during the enrolment. As the health camp received more male subjects the prevalence rate has gone up in this study.

It is evident that as the age progresses, the prevalence of fatty liver goes up till 50 years and again decreases in the age group of 50 - 59 years and above 60 years. This trend was similar to the trend observed by $\mathrm{Li} \mathrm{H}$ et al. This trend can be attributed to decreased levels of androsterone in males as the age progresses as majority involved in this study were males.[11] And in this study, out of 7 females who presented with fatty liver, 4 are in the age group of $50-59$ years. This again stresses the fact that increased androsterone and decreased oestrogens after menopause to be regarded as one of the risk factors for NAFLD.[11]

There was a 4.5 fold increase in prevalence of NAFLD among males when compared with females. This is due to the fact that female subjects enrolled were meagre in number compared to the male population and also prevalence in female population is less in reproductive years due to the phenomenon explained above.

Several studies have been done to show the association of higher levels of biochemical parameters in subjects with NAFLD. Higher levels of total cholesterol has been seen in subjects with NAFLD along with other biochemical parameters as given in a review article by Neumann MG et al[12,13] In this study also, we came across higher levels of total cholesterol in fatty liver subjects when compared to normal subjects. And the results obtained were very much significant when the mean total cholesterol values were compared between diseased and normal subjects $(\mathrm{p}=$ $0.0014)$.

\section{CONCLUSION}

In the present study, ultrasonography was used as the method for diagnosing the cases of fatty liver and the prevalence obtained was around $60 \%$. The high prevalence could be due to the bias of investigative modality or could be due to gender bias. The mean cholesterol values of the diseased when compared with the normal subjects was significantly higher, proves that high total cholesterol values can be associated with fatty liver and vice versa. Thus, it makes sense to screen subjects with high total cholesterol for fatty liver and vice versa, so that they can be treated and managed early and prevent them from developing metabolic syndrome.

\section{REFERENCES}

[1] Onyekwere CA, Ogbera AO, Samaila AA, et al. Nonalcoholic fatty liver disease: synopsis of current developments. Niger J Clin Pract 2015;18(6):703-12.

[2] Milic S, Mikolasevic I, Krznaric-Zrnic I, et al. Nonalcoholic steatohepatitis: emerging targeted therapies to optimize treatment options. Drug Design Development and Therapy 2015;9:4835-45.

[3] Perera N, Indrakumar J, Abeysinghe WV, et al. Non alcoholic fatty liver disease increases the mortality from acute coronary syndrome: an observational study from Sri Lanka. BMC Cardiovascular Disorders 2016;16:37.

[4] Hernandez-Rodas MC, Valenzuela R, Videla LA. Relevant Aspects of Nutritional and Dietary Interventions in Non-Alcoholic Fatty Liver Disease. International Journal of Molecular Sciences 2015;16(10):25168-98.

[5] Salvoza NC, Klinzing DC, Gopez-Cervantes J, et al. Association of circulating serum miR-34a and miR-122 with dyslipidemia among patients with non-alcoholic fatty liver disease. PLoS ONE 2016;11(4):e0153497.

[6] Zhang B, Ding F, Chen $T$, et al. Ultrasound hepatic/renal ratio and hepatic attenuation rate for quantifying liver fat content. World Journal of Gastroenterology 2014;20(47):17985-92.

[7] Goulart AC, Oliveira IR, Alencar AP, et al. Diagnostic accuracy of a noninvasive hepatic ultrasound score for non-alcoholic fatty liver disease (NAFLD) in the Brazilian longitudinal study of adult health (ELSABrasil). Sao Paulo Medical Journal 2015;133(2):11524. 


\section{Jemds.com}

[8] Takata Y, Ansai T, Soh I, et al. Serum total cholesterol concentration and 10-year mortality in an 85-year-old population. Clinical Interventions in Aging 2014;9:293-300.

[9] Jeong T-D, Lee W, Choi S-E, et al. Relationship between serum total cholesterol level and serum biochemical bone turnover markers in healthy pre- and postmenopausal women. BioMed Research International Article ID 398397, 2014;2014:7.

[10] Liao X-H, Cao X, Liu J, et al. Prevalence and features of fatty liver detected by physical examination in Guangzhou. World Journal of Gastroenterology 2013;19(32):5334-9.

\section{Original Research Article}

[11] Li H, Wang YJ, Tan K, et al. Prevalence and risk factors of fatty liver disease in Chengdu, Southwest China. Hepatobiliary Pancreat Dis Int 2009;8(4):377-82.

[12] Neuman MG, Cohen LB, Nanau RM. Biomarkers in nonalcoholic fatty liver disease. Can J Gastroenterol Hepatol 2014;28(11):607-18.

[13] Gokulakrishnan K, Anjana RM, Indulekha $\mathrm{K}$, et al. Association of hypoadiponectinemia with nonalcoholic fatty liver disease in urban south Indians(CURES-81). Indian J Med Res 2010;132:271-7. 